\title{
Atomistic Understanding of the Peculiar Dissolution Behavior of Alkaline Polymer Electrolytes in Alcohol/Water Mixed Solvents
}

\author{
LYU Kangjie ${ }^{1}$, PENG Yanqiu ${ }^{1}$, XIAO Li 1, ${ }^{*}$, LU Juntao ${ }^{1}$, ZHUANG Lin ${ }^{1,2,{ }^{*}}$ \\ ${ }^{1}$ Hubei Key Lab of Electrochemical Power Sources, College of Chemistry and Molecular Sciences, Wuhan 430072, P. R. China. \\ ${ }^{2}$ Institute for Advanced Studies, Wuhan University, Wuhan 430072, P. R. China.
}

\begin{abstract}
Self-aggregated quaternary ammonium polysulfone (aQAPS) is a highperformance alkaline polymer electrolyte that has been applied in alkaline polymer electrolyte fuel cells (APEFCs). For a long time, $N, N$-dimethyl formamide (DMF) has been considered the best solvent to dissolve aQAPS, but the high boiling point of DMF makes it hard to remove from the electrodes, which potentially poisons the electrocatalysts. Our recent experiments have shown that although aQAPS is unable to dissolve in ethanol, $n$ propanol, or water, it can dissolve in the mixture of these alcohols and water. This peculiar dissolution behavior significantly facilitates the fabrication of the membrane electrode assembly (MEA) for APEFCs, even though it has not been understood. In this work, atomistic molecular dynamics (MD) simulations were employed to study the dissolution behavior of aQAPS in different solvents, including water, methanol, ethanol, $n$-propanol, DMF, and the mixture of these non-aqueous solvents and water. The conformation of the aQAPS chain in pure solvents agreed well with the dissolution behavior observed in the experiments, even though in the water-containing mixed solvents, the aQAPS chain tended to be in a more contracted state. The simulations further revealed that the water component in the mixed solvents played dual roles. On one hand, the hydrocarbon chain of aQAPS was compressed to a contracted state upon the addition of water, because of the hydrophobic effect. On the other hand, water can drive the dissociation of the counterion $\left(\mathrm{Cl}^{-}\right)$, which led to an enhancement in the solute-solvent interaction energy and thus facilitated the dissolution of aQAPS. In most mixed solvents, the compensation of these two interactions resulted in a general increase in the total solute-solvent interaction energy; therefore, the addition of water was energetically favorable for the dissolution of aQAPS. This study not only furthers our fundamental understanding of the dissolution behavior of polyelectrolytes but also is technologically significant for the development of better APEFCs.
\end{abstract}

Key Words: Alkaline polymer electrolyte; Dissolution; Alcohol/water mixed solvents; Molecular dynamics simulation

\section{醇/水混合溶剂中碱性聚合物电解质独特的溶解行为}

\author{
吕康杰 ${ }^{1}$, 彭燕秋 ${ }^{1}$, 肖丽 ${ }^{1, *}$, 陆君涛 1 , 庄林 $1,2,{ }^{*}$ \\ 1 武汉大学化学与分子科学学院, 化学电源材料与技术湖北省重点实验室, 武汉 430072 \\ 2 武汉大学高等研究院, 武汉 430072
}

摘要: 自聚集型季铵化聚砜( $\mathrm{aQAPS}$ )是一种高性能的碱性聚合物电解质(APE), 已被应用于碱性聚合物电解质燃料电池 (APEFCs)中。长期以来, $N, N$-二甲基甲酰胺(DMF)一直被作为溶解 $\mathrm{aQAPS}$ 的最佳溶剂, 但 DMF 的高沸点使其难以彻

Received: April 9, 2018; Revised: May 2, 2018; Accepted: May 2, 2018; Published online: May 3, 2018.

*Corresponding authors. Email: chem.lily@whu.edu.cn (X.L.). Email: lzhuang@whu.edu.cn; Tel.: +86-27-68753833 (Z.L.).

The project was supported by the National Key Research and Development Program of China (2016YFB0101203) and the National Natural Science Foundation of China (91545205, 21633008).

国家重点研发计划(2016YFB0101203)和国家自然科学基金(91545205, 21633008)资助项目

(C) Editorial office of Acta Physico-Chimica Sinica 
底除尽并可能会毒化电催化剂。在我们最近的实验中发现, 虽然aQAPS不能溶解于乙醇、正丙醇或水中, 但它可以溶解 在这些醇和水的混合物中。这种尚未被理解的独特溶解行为能够极大地促进APEFCs中膜电极组件(MEA)的制备。本工 作使用分子动力学(MD)模拟的方法研究了 $\mathrm{QQAPS}$ 在不同溶剂中的溶解行为, 包括水、甲醇、乙醇、正丙醇、DMF以及 这些非水溶剂与水的混合物。aQAPS链在单一溶剂中的构象与其在实验中观察到的溶解行为一致, 但在含有水的混合溶 剂中, aQAPS链往往处于更加蜷缩的状态。模拟结果进一步揭示了混合溶剂中的水扮演着双重角色。一方面, 由于疏水 作用, aQAPS链在加水时被压缩至收缩状态; 另一方面, 水可以驱动反离子 $\left(\mathrm{Cl}^{-}\right)$的离解, 从而导致溶质-溶剂相互作用 能的增强, 促进aQAPS的溶解。在大多数混合溶剂中, 这两种相互作用的总效果是增大了总的溶质-溶剂相互作用能, 在 能量上有利于aQAPS 的溶解。本研究不仅能够加深我们对聚电解质溶解行为的基本认识, 而且对于开发性能更优的 APEFCs也具有技术指导作用。

关键词: 碱性聚合物电解质; 溶解; 醇/水混合溶剂; 分子动力学模拟 中图分类号：0643

\section{Introduction}

Alkaline polymer electrolytes (APEs) are a key material for alkaline polymer electrolyte fuel cells (APEFCs) ${ }^{1,2}$, a new class of fuel-cell technology featuring the use of non-precious metal catalysts ${ }^{3-6}$. A variety of APEs have been reported in recent years, among them, the self-aggregated quaternary ammonium polysulfone (aQAPS) is rather promising, due to its superior $\mathrm{OH}^{-}$conductivity and high chemical/physical stability ${ }^{4,7-9}$. APEFCs using aQAPS have achieved a peak power density over $1 \mathrm{~W} \cdot \mathrm{cm}^{-2}$, comparable to the performance of proton exchange membrane fuel cells (PEMFCs) ${ }^{10}$. However, the properties of aQAPS have not been fully understood, in particular its dissolution behavior. The aQAPS usually dissolves in $\mathrm{N}, \mathrm{N}$ dimethyl formamide (DMF), a high boiling point solvent that is hard to completely remove from the electrodes and would cause poisoning effect on electrocatalysis ${ }^{11}$. So far, very limited theoretical and experimental efforts have been devoted to the study of the dissolution behavior of APEs ${ }^{12,13}$. The lack of indepth understanding of APEs has been a barrier to further improving the performance of APEFCs.

Recently we found that, although aQAPS cannot dissolve in ethanol, $n$-propanol, or water, it is soluble in mixtures of these alcohol and water. This finding not only enables the replacement of DMF with green and volatile solvents, but also greatly facilitates the preparation of the membrane electrode assembly (MEA) for APEFCs. In order to understand this peculiar dissolution behavior of aQAPS, we employed atomistic molecular dynamics (MD) simulations to study the solvation of aQAPS in different solvents, including water, methanol, ethanol, n-propanol, DMF, and the mixture of these non-aqueous solvents and water. Based on information gained from these MD simulations, the seemingly peculiar dissolution behavior of aQAPS now becomes understandable.

\section{Methods}

The chemical formula for aQAPS is shown in Fig. 1.

The classical atomistic MD simulations were carried out using Gromacs ${ }^{14}$. We considered a single diblock chain $(m=1, n=1$, $k=5$ in Fig. 1) in the simulation. The two different chain blocks were built into the GAFF-based force field with ACPYPE ${ }^{15}$ and ANTECHAMBER ${ }^{16}$. Their partial charges were obtained by taking the middle part of three repeat chain blocks using the AM1-BCC method ${ }^{17}$. The GAFF force field with RESP charge method was chosen for propanol while the parameters for other solvents were get from literature ${ }^{18} .5$ chlorine ions were added for electro-neutrality. As for water, we used the SPC/E model ${ }^{19}$, water molecular bonds were kept rigid using the SETTLE algorithm ${ }^{20}$. The results were visualized using VMD package ${ }^{21}$.

Cubic simulation boxes were used with the length around 6 $\mathrm{nm}$, corresponding to a concentration of $41 \mathrm{mg} \cdot \mathrm{mL}^{-1}$ similar to that in practice $\left(20 \mathrm{mg} \cdot \mathrm{mL}^{-1}\right)$. All simulations were carried out in NPT ensembles. The temperature was kept at $300 \mathrm{~K}$ using the Nosé-Hoover thermostat ${ }^{22}$ and the pressure was kept at $0.1 \mathrm{MPa}$ using a Parrinello-Rahman barostat ${ }^{23}$. The cut-off for shortrange interactions was $1.2 \mathrm{~nm}$ and the particle-mesh Ewald method ${ }^{24}$ was used to account for long-range electrostatics. A time step of $2 \mathrm{fs}$ was used for most simulation, while for systems with DMF a reduced time step of $1 \mathrm{fs}$ was used.

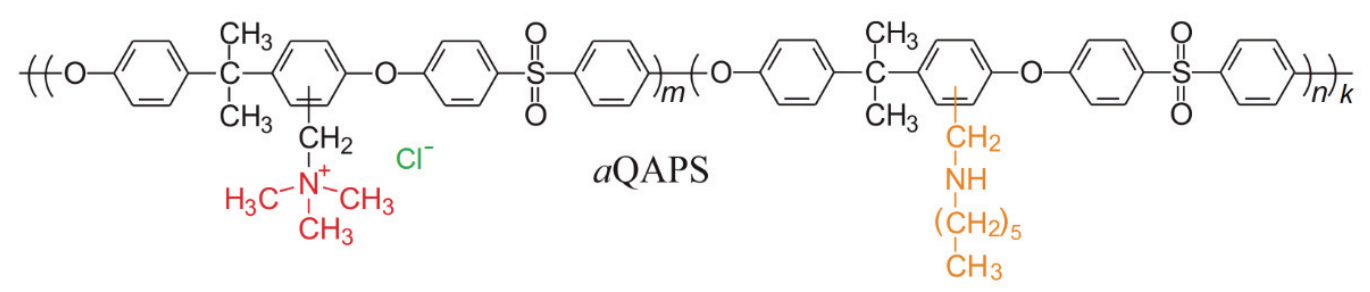

Fig. 1 The molecular structure of aQAPS. 
The pure solvent boxes were all well equilibrated for $2 \mathrm{~ns}$ before used in the solvation process. Two initial conformations, contracted state or spread state, were put into the box with all overlapped solvent molecules deleted. For the mixed solvents, half of the residual solvent molecules were deleted randomly, and then water was added to fill the box again.

Each system was simulated for up to $100 \mathrm{~ns}$ with the coordinates saved every 1 ps. The last $20 \mathrm{~ns}$ of each system was used to analyze the interactions and the RDFs.

The dissolution experiment has been carried out as follows: aQAPS was synthesized from the DMF solution of polysulfone ${ }^{7}$. The powder of aQAPS was prepared by dropping the solution into ether carefully. The precipitation was then filtered by ether and dried at $50{ }^{\circ} \mathrm{C}$ for $10 \mathrm{~h}$. The dry aQAPS powder was put into 10 centrifuge tubes $(0.10 \mathrm{~g}$ aQAPS powder per tube), and different solvent $(5 \mathrm{~mL})$ was then added to corresponding tube followed by ultrasonic stirring. These tubes were then kept in a $70{ }^{\circ} \mathrm{C}$ water bath for $5 \mathrm{~h}$. The maximum mass fraction of aQAPS in different solvents (Table 1) was obtained by weighting the dissolved aQAPS in saturated solutions after evaporating the solvent.

\section{Results and discussion}

\subsection{Experimental observations of the peculiar dissolution behavior of aQAPS}

The solubility of aQAPS in nine testing solvents is described by the maximum mass fraction of aQAPS and listed in Table 1. The solvents include five pure solvents (water, DMF, methanol, ethanol, and $n$-propanol) and four mixed solvents (50\% (volume fraction) of water and $50 \%$ (volume fraction) of non-aqueous solvents), namely, DMF/water, methanol/water, ethanol/water, and $n$-propanol/water. Clearly, the aQAPS can well dissolve in DMF and methanol, but not in water, ethanol, or $n$-propanol. Surprisingly, the aQAPS can dissolve well in the alcohol/water mixed solvents. These observations indicate that water is playing a pivotal, but not yet understood, role in the dissolution of aQAPS.

In order to unravel the molecular details of the dissolution behavior of aQAPS, atomistic MD simulations were performed to study the dynamic conformation of aQAPS in different

(a)

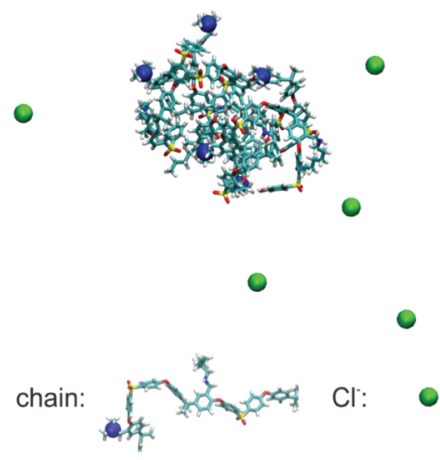

Table 1 Maximum mass fraction of aQAPS dissolved in studied solvents at room temperature.

\begin{tabular}{cccc}
\hline Pure solvent & Mass fraction/\% & Mixed solvent & Mass fraction $\%$ \\
\hline water & 0.0 & methanol/water & 1.6 \\
methanol & 1.2 & ethanol/water & 1.1 \\
ethanol & 0.0 & $n$-propanol/water & 0.8 \\
$n$-propanol & 0.0 & DMF/water & 1.8 \\
DMF & 1.0 & & \\
\hline
\end{tabular}

solvents.

\subsection{The initial conformation of aQAPS chain in MD simulations}

MD simulations of an aQAPS chain (10 mer) were first performed in two typical solvents, water and DMF. Since water is a bad solvent for aQAPS, the aQAPS chain was compressed into a contracted state in water as expected (Fig. 2a). In contrast, the aQAPS chain remained in a spread state in DMF (Fig. 2b). We took these two conformations of aQAPS as the initial states, contracted and spread states, in the following simulations for aQAPS in different solvents. The dynamics of the aQAPS conformation was monitored by typical properties, such as the chain dimension, the interaction energy, and the radial distribution function.

\subsection{The evolution of polymer chain dimension in pure solvents}

The dimension of the aQAPS polymer chain can be described by the radius of gyration $\left(R_{\mathrm{g}}\right)^{25,26}$. Fig. 3a shows the time evolution of $R_{\mathrm{g}}$ of the aQAPS chain with an initially contracted state in pure solvents. The average value of $R_{\mathrm{g}}$ was calculated by the last $20 \mathrm{~ns}$ of individual trajectories. In water, the $R_{\mathrm{g}}$ of the aQAPS chain reached a value of $1.07 \mathrm{~nm}$, mostly remaining the contracted initial conformation. In DMF, on the other hand, the aQAPS chain became fully expanded and the $R_{\mathrm{g}}$ reached a value of $2.39 \mathrm{~nm}$, the greatest value for aQAPS in all pure solvents. The $R_{\mathrm{g}}$ of aQAPS in methanol was about $1.71 \mathrm{~nm}$, indicating that methanol can also stretch the aQAPS chain to a spread state. In ethanol and $n$-propanol, however, the $R_{\mathrm{g}}$ was relatively small (1.26 and $1.40 \mathrm{~nm}$, respectively). These simulation results are in good agreement with the experimental observations (Table 1), namely, DMF and methanol are good solvents for aQAPS, while

(b)

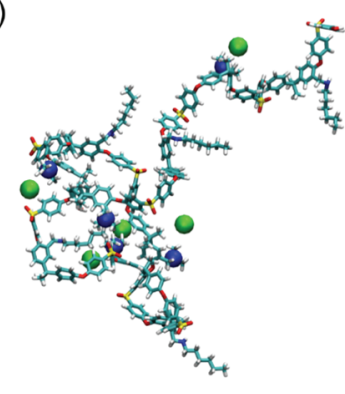

Quaternary ammonium:

Fig. 2 The contracted state (a) and spread state (b) of an aQAPS chain in water and DMF, respectively, resulted from MD simulations. 

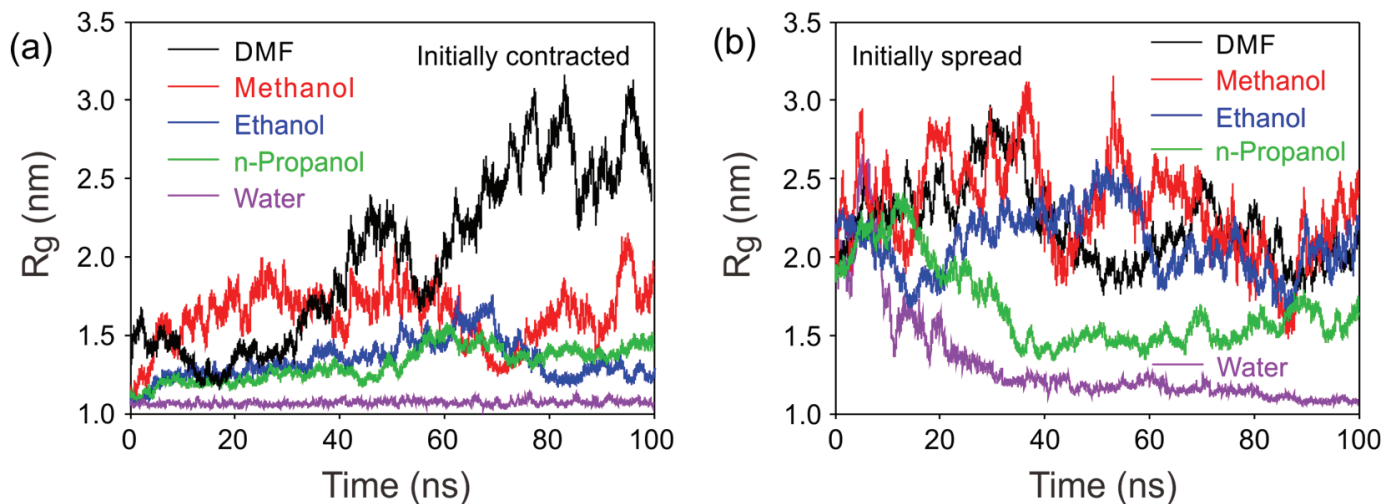

Fig. 3 Time evolution of the radius of gyration $\left(R_{\mathrm{g}}\right)$ of the aQAPS chain in pure solvent.

Simulations were started from an initially contracted state (a) or an initially spread state (b).

ethanol and $n$-propanol can only make aQAPS slightly swollen, and water cannot dissolve aQAPS at all.

For comparison, the MD simulations were also performed with the aQAPS chain of spread initial conformation. The simulation results (Fig. 3b) show that, in DMF, methanol, and ethanol, the final $R_{\mathrm{g}}$ of the aQAPS chain was 2.00, 2.04, and 1.96 $\mathrm{nm}$, respectively, indicating the aQAPS chain remained in the spread state as its initial conformation, even the MD simulation was kept running for a much longer period (250 ns). The simulation result for aQAPS in ethanol was different from the previous simulation with contracted initial state, and also seems to disagree with the experimental observation. This inconsistency is due to the fact that the initial conformation of the aQAPS chain was, in this case, deliberately set in a spread state, which turns out to be also a stable state in ethanol. In other words, there is no sufficient driving force in ethanol to change the conformation of the aQAPS chain, be it initially in a contracted or spread state.

\subsection{The contraction of polymer chains in water- containing mixed solvents}

The time evolution of $R_{\mathrm{g}}$ of aQAPS in mixed solvents is shown in Fig. 4. Generally speaking, the aQAPS chain tended to be in a more contracted state in mixed solvents than in pure solvents, regardless what initial conformation was used in the simulations. For example, when the simulation was started from an initially contracted state (Fig. 4a), the stretching of the aQAPS chain in DMF/water mixed solvent was more difficult than in pure DMF, and the final $R_{\mathrm{g}}$ was only $1.30 \mathrm{~nm}$ (in comparison to $2.39 \mathrm{~nm}$ in pure DMF). The resulting $R_{\mathrm{g}}$ in other mixed solvents was even smaller. When the simulations were started with a spread initial state (Fig. $4 \mathrm{~b}$ ), the $R_{\mathrm{g}}$ of aQAPS chain was reduced in all mixed solvents, in comparison to that in pure solvents. For example, the resulting $R_{\mathrm{g}}$ was $1.5 \mathrm{~nm}$ in DMF/water mixed solvent, and even smaller in other mixed solvents.

The above simulation results can be explained by the hydrophobic effect of the aQAPS chain. By adding water into DMF or alcohols, the hydrocarbon chain was squeezed by water molecules, despite the existence of DMF or alcohol molecules. These simulation results seem to be inconsistent to the experimental observations, where aQAPS can dissolve well in these mixed solvents. Such a seemingly contradictory implies the existence of another factor that dominates the dissolution behavior of aQAPS in these mixed solvents.

\subsection{Analysis on the free energy change of dissolving aQAPS in mixed solvents}

Since the solubility of aQAPS in water-containing mixed solvents cannot be explained by the change in polymer conformation, the change in free energy $(\Delta G)$, consisting of enthalpy change $(\Delta H)$ and entropy change $(-T \Delta S)$, should be a
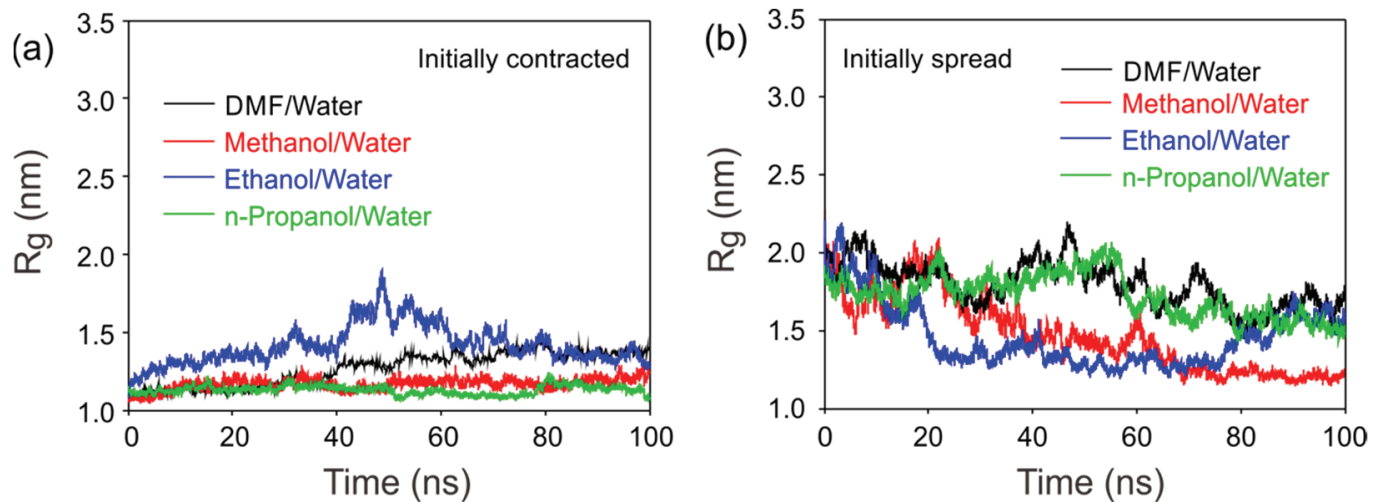

Fig. 4 Time evolution of the radius of gyration $\left(R_{\mathrm{g}}\right)$ of the aQAPS chain in mixed solvent. 
driving factor. The $\Delta S$ upon adding water can be analyzed as the following. Based on the simulated $R_{\mathrm{g}}$ of aQAPS in pure solvents (Fig. 2), the polymer chain is at the most compressed/confined state in water, while freer to move in alcohols or DMF. In other words, mixing aQAPS with alcohols or DMF will result in a greater entropy than with water ${ }^{27}$. Therefore, adding water into the aQAPS/alcohols or aQAPS/DMF systems will cause a reduction in entropy ${ }^{28}$, namely, a positive contribution of the $-T \Delta S$ term to the $\Delta G$, which turns out not to be a driving force for dissolving aQAPS in mixed solvents.

Consequently, the dissolution behavior of aQAPS in mixed solvents can only be ascribed to the $\Delta H$, which is determined by the interactions between aQAPS and solvent molecules, as to be calculated in the following sections.

\subsection{The change in interaction energies upon water addition}

To consider the driving force for the dissolution of aQAPS upon adding water, the change in the interaction between the solvent and the polymer chain and the ionization effect (the dissociation of the counterions) have to be taken into account ${ }^{29,30}$. On the one hand, the addition of water causes the contraction of the hydrocarbon chain of aQAPS (i.e., the hydrophobic effect); on the other hand, it can drive the dissociation of the counterion $\left(\mathrm{Cl}^{-}\right.$in this case) from the cationic backbone. To qualitatively evaluate these effects on the dissolution behavior of the aQAPS, we calculated the columbic attraction between the cationic polymer chain and the counterion, as well as the interaction between the polymer and solvent molecules, to see how these interaction energies change upon water addition.

Fig. 5a illustrates the change in the columbic attraction energy between the cationic backbone and the $\mathrm{Cl}^{-}$. Whereas the columbic attraction was strong in pure non-aqueous solvents; it became much weaker in water because of the dissociation of $\mathrm{Cl}^{-}$. In mixed solvents, the columbic attraction between the cationic backbone and the $\mathrm{Cl}^{-}$turned out to be substantially reduced to a level close to that in water, showing that the $\mathrm{Cl}^{-}$can also be dissociated in water-containing mixed solvents.

The change in the total solute-solvent interaction energy upon

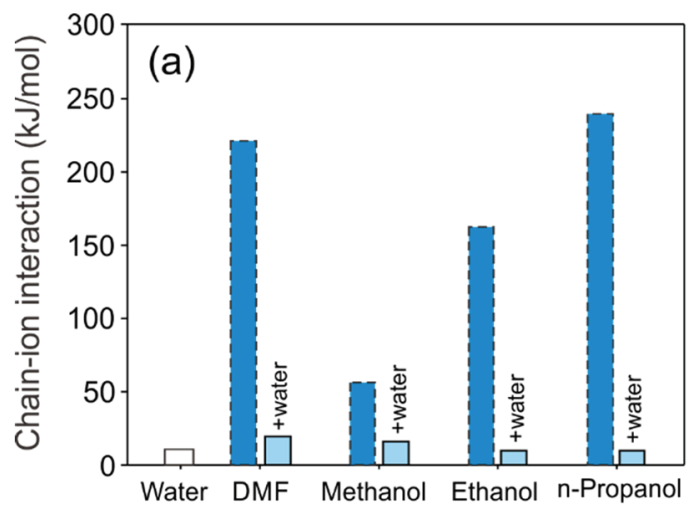

water addition is then mostly determined by the competition of the hydrophobic effect and the ionization effect. As presented in Fig. $5 \mathrm{~b}$, the total solute-solvent interaction energy includes the solvent-counterion interaction (green bars) and the solventpolymer chain interaction (white bars). Whereas the solventcounterion interaction energies were enhanced due to the ionization effect, the solvent-polymer chain interaction energies were reduced, to some degree, due to the hydrophobic effect. The compensation of these two interaction energies resulted in a general increase in the total solute-solvent interaction energy, by a magnitude of hundreds of $\mathrm{kJ} \cdot \mathrm{mol}^{-1}$, indicating that the addition of water was energetically favorable to the dissolution of aQAPS

An exception was found in the interaction energy change. When water was added into methanol, the total solute-solvent interaction energy was decreased, rather than increased as in other mixed solvents. This is because $\mathrm{Cl}^{-}$can also be dissociated in pure methanol (vide infra), the addition of water did not cause a significant enhancement in the solvent- $\mathrm{Cl}^{-}$interaction energy, and the total interaction energy was thus not increased. Note that this does not hamper the dissolution of aQAPS in methanol/water solvent, since aQAPS is soluble in pure methanol and $\mathrm{Cl}^{-}$is dissociated in the methanol/water mixed solvent.

\subsection{Radial distribution functions of the system}

The radial distribution functions (RDF) of the components in the system were calculated to enrich the structural information of aQAPS in the pure/mixed solvents. The distribution of ions and water molecules in the system were studied by calculating the $\mathrm{RDF}$ of $\mathrm{Cl}-\mathrm{N}$ and $\mathrm{Cl}-\mathrm{O}_{\mathrm{w}}$, where $\mathrm{N}$ refers to the quaternary ammonium group of aQAPS (with the nitrogen atom marked as $\mathrm{N}$ ), and $\mathrm{O}_{\mathrm{w}}$ refers to the water molecules (with the oxygen atom marked as $\mathrm{O}_{\mathrm{w}}$ ).

Fig. 6a shows the RDF of $\mathrm{Cl}-\mathrm{N}\left(g_{\mathrm{Cl}-\mathrm{N}}\right)$, referring to the distribution of quaternary ammonium groups around $\mathrm{Cl}^{-}$. In most organic solvents (dashed lines), a strong peak of $\mathrm{N}$ was found around $\mathrm{Cl}^{-}$, indicating that the $\mathrm{Cl}^{-}$and the quaternary ammonium groups have formed close ion pairs. In methanol,

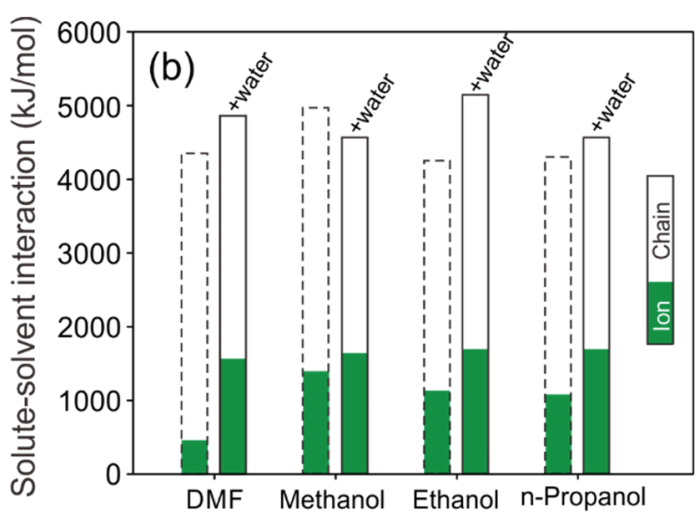

Fig. 5 The interaction energy between the cationic polymer chain and the counterion (a), and between the solvent and the solute (b), including the polymer chain and the counterion, in pure and mixed solvents. 

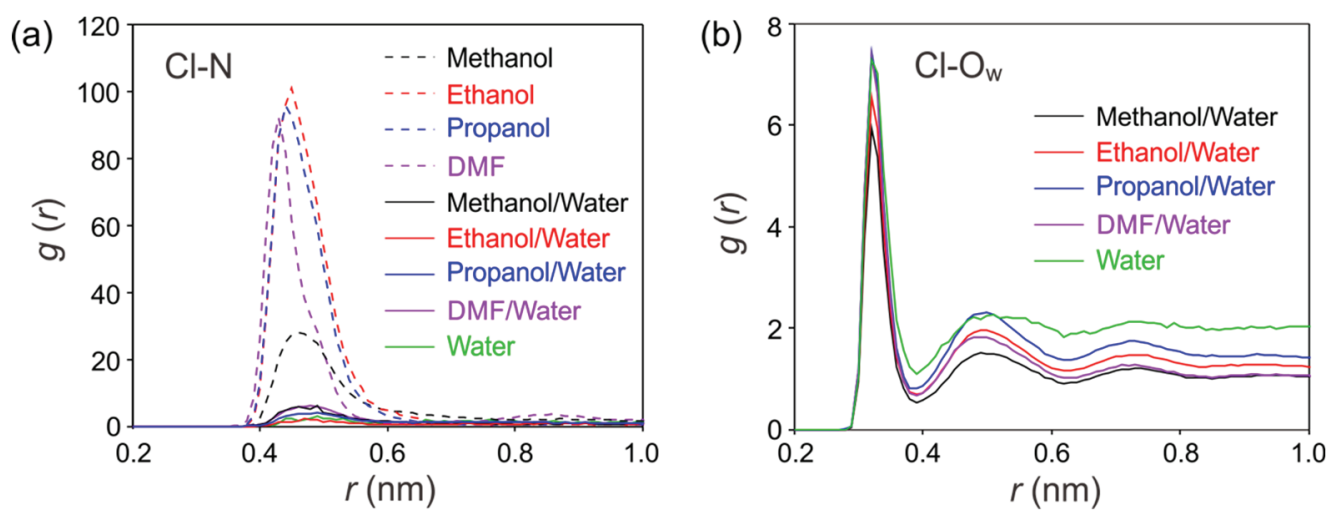

Fig. 6 The radial distribution functions (RDFs) for the quaternary ammonia group (a) and the water molecules

(b) around the $\mathrm{Cl}^{-}$in pure/mixed solvents.

however, the peak of $\mathrm{N}$ around $\mathrm{Cl}^{-}$was relatively weak, indicating that the $\mathrm{Cl}^{-}$was able to be dissociated in methanol. The $g_{\mathrm{Cl}-\mathrm{N}}$ was greatly reduced in all mixed solvents (solid lines), indicating that the $\mathrm{Cl}^{-}$was dissociated and away from the quaternary ammonium groups.

Fig. $6 \mathrm{~b}$ shows the $\mathrm{RDF}$ of $\mathrm{Cl}^{-}-\mathrm{O}_{\mathrm{w}}\left(\mathrm{g}_{\mathrm{Cl}-\mathrm{Ow}}\right)$. The larger the $g_{\mathrm{Cl}-\mathrm{Ow}}$, the more water molecules around $\mathrm{Cl}^{-}$. The first layer of water molecules around $\mathrm{Cl}^{-}$(within $0.4 \mathrm{~nm}$ ) is the hydration layer of $\mathrm{Cl}^{-}$. In all mixed solvents, such a hydration layer around $\mathrm{Cl}^{-}$was almost completely preserved. Organic molecules with hydroxyl group can approach the $\mathrm{Cl}^{-}$to some degree, thus the $g_{\mathrm{Cl}-\mathrm{Ow}}$ of $\mathrm{Cl}^{-}$hydration layer was somewhat reduced in mixed solvents, with an order of $\mathrm{DMF} /$ water $\approx n$-propanol/water $>$ ethanol/water $>$ methanol/water.

The above analysis shows that the main difference in RDFs between mixed and pure solvents is mainly due to the dissociation of $\mathrm{Cl}^{-}$. This ionization effect leads to the repulsion of positive charged aQAPS, which can then improve the stability of the dispersion of the polymer chains and thus promote the dissolution of aQAPS.

\section{Conclusions}

In this work, atomistic MD simulations were employed to study the dissolution behavior of aQAPS in different solvents, including water, methanol, ethanol, $n$-propanol, DMF, and the mixture of the above non-aqueous solvents and water. The dissolution behavior of aQAPS in pure solvents can be interpreted in terms of the radius of gyration $\left(R_{\mathrm{g}}\right)$ of the polymer chain. The aQAPS is soluble in DMF and methanol because the polymer chain is well spread in these solvents, while the aQAPS cannot dissolve in water, ethanol, and $n$-propanol, as the polymer chain is contracted in these solvents. In water-containing mixed solvents, however, the conformational change of polymer chain cannot account for the dissolution behavior, the free energy change upon water addition has to be considered. Since the change in the entropy term $(-T \Delta S)$ is positive on adding water into the system, the driving force for dissolving aQAPS in mixed solvent can only be ascribed to the enthalpy change, which is mainly determined by the solute-solvent interaction.
Calculations show that the solute-solvent interaction was enhanced upon water addition mostly due to the dissociation of $\mathrm{Cl}^{-}$and the thus enhanced interaction between the $\mathrm{Cl}^{-}$and water molecules. The RDFs of the quaternary ammonia group and the water molecules around the $\mathrm{Cl}^{-}$provide a clear picture that the $\mathrm{Cl}^{-}$was surrounded by water molecules and dragged away from the polymer chain.

In conclusion, there are two ways to dissolve aQAPS: one is to dissolve aQAPS in pure solvents that can stretch the polymer chain to a fully spread state. The other is to dissolve aQAPS in mixed solvents, in which the counterions can be dissociated, no matter the polymer chains are contracted or spread, as long as the ionization effect is stronger than the hydrophobic effect.

These atomistic pictures and understandings are not only held for the dissolution behavior of aQAPS, but can also be applied to other APEs in similar structures. The solubility of aQAPS, and other alike APEs, in water/alcohol mixed solvents, is an important finding that can help the development of better APEFC technology.

\section{References}

(1) Varcoe, J. R.; Atanassov, P.; Dekel, D. R.; Herring, A. M.; Hickner, M. A.; Kohl, P. A.; Kucernak, A. R.; Mustain, W. E.; Nijmeijer, K.; Scott, K.; et al. Energy Environ. Sci. 2014, 7, 3135. doi: 10.1039/C4EE01303D

(2) Merle, G.; Wessling, M.; Nijmeijer, K. J. Memb. Sci. 2011, 377, 1. doi: 10.1016/j.memsci.2011.04.043

(3) Asazawa, K.; Yamada, K.; Tanaka, H.; Oka, A.; Taniguchi, M.; Kobayashi, T. Angew. Chem. -Int. Ed. 2007, 46, 8024. doi: 10.1002/anie.200701334

(4) Lu, S. F.; Pan, J.; Huang, A. B.; Zhuang, L.; Lu, J. T. Proc. Natl. Acad. Sci. USA 2008, 105, 20611. doi: 10.1073/pnas.0810041106

(5) Chakraborty, S.; Ghaisas, S. V.; Majumder, C. Eur. Phys. J. B 2012, 85, 227. doi: 10.1140/epjb/e2012-20591-7

(6) Varcoe, J. R.; Slade, R. C. T.; Wright, G. L.; Chen, Y. J. Phys. Chem. B 2006, 110, 21041. doi: 10.1021/jp064898b

(7) Pan, J.; Chen, C.; Li, Y.; Wang, L.; Tan, L.; Li, G.; Tang, X.; Xiao, 
L.; Lu, J.; Zhuang, L. Energy Environ. Sci. 2014, 7, 354. doi: 10.1039/C3EE43275K

(8) Chen, C.; Pan, J.; Han, J.; Wang, Y.; Zhu, L.; Hickner, M. A.;

Zhuang, L. J. Mater. Chem. A 2016, 4, 4071.

doi: 10.1039/C5TA09438K

(9) Pan, J.; Li, Y.; Han, J.; Li, G.; Tan, L.; Chen, C.; Lu, J.; Zhuang, L. Energy Environ. Sci. 2013, 6, 2912. doi: 10.1039/c3ee41968a

(10) Wang, Y.; Wang, G.; Li, G.; Huang, B.; Pan, J.; Liu, Q.; Han, J.; Xiao, L.; Lu, J.; Zhuang, L. Energy Environ. Sci. 2015, 8, 177. doi: 10.1039/C4EE02564D

(11) Anastas, P.; Eghbali, N. Chem. Soc. Rev. 2010, 39, 301 doi: 10.1039/B918763B

(12) Filimon, A.; Avram, E.; Ioan, S. Polym. Bull. 2013, 70, 1835. doi: $10.1007 / \mathrm{s} 00289-012-0874-\mathrm{Z}$

(13) Ioan, S.; Filimon, A.; Avram, E. J. Macromol. Sci. Part B 2005, 44, 129. doi: 10.1081/MB-200044623

(14) Abraham, M. J.; Murtola, T.; Schulz, R.; Páll, S.; Smith, J. C.; Hess, B.; Lindah, E. SoftwareX 2015, 1-2, 19. doi: 10.1016/j.softx.2015.06.001

(15) Sousa da Silva, A. W.; Vranken, W. F. BMC Res. Notes 2012, 5, 367 doi: $10.1186 / 1756-0500-5-367$

(16) Wang, J. M.; Wolf, R. M.; Caldwell, J. W.; Kollman, P. A.; Case, D. A. J. Comput. Chem. 2004, 25, 1157. doi: 10.1002/jcc. 20035

(17) Jakalian, A.; Jack, D. B.; Bayly, C. I. J. Comput. Chem. 2002, 23, 1623. doi: $10.1002 /$ jcc. 10128

(18) Caleman, C.; Van Maaren, P. J.; Hong, M.; Hub, J. S.; Costa, L. T.;
Van Der Spoel, D. J. Chem. Theory Comput. 2012, 8, 61. doi: $10.1021 /$ ct200731v

(19) Berendsen, H. J. C.; Grigera, J. R.; Straatsma, T. P. J. Phys. Chem. 1987, 91, 6269. doi: 10.1021/j100308a038

(20) Miyamoto, S.; Kollman, P. A. J. Comput. Chem. 1992, 13, 952. doi: $10.1002 /$ jcc. 540130805

(21) Humphrey, W.; Dalke, A.; Schulten, K. J. Mol. Graph. 1996, 14, 33. doi: 10.1016/0263-7855(96)00018-5

(22) Evans, D. J.; Holian, B. L. J. Chem. Phys. 1985, 83, 4069. doi: $10.1063 / 1.449071$

(23) Martoňák, R.; Laio, A.; Parrinello, M. Phys. Rev. Lett. 2003, 90, 075503. doi: 10.1103/PhysRevLett.90.075503

(24) Essmann, U.; Perera, L.; Berkowitz, M. L.; Darden, T.; Lee, H.; Pedersen, L. G. J. Chem. Phys. 1995, 103, 8577. doi: $10.1063 / 1.470117$

(25) Mukherji, D.; Marques, C. M.; Kremer, K. Nat. Commun. 2014, 5, 4882. doi: $10.1038 /$ ncomms 5882

(26) Fixman, M. J. Chem. Phys. 1962, 36, 306. doi: 10.1063/1.1732501

(27) Madkour, T. M. Chem. Phys. 2001, 274, 187. doi: 10.1016/S0301-0104(01)00507-9

(28) Silverstein, T. P. J. Chem. Educ. 1998, 75, 116. doi: 10.1021/ed075p116

(29) Mark, H. Sci. Mon. 1954, 79, 508.

(30) Pavlopoulou, E.; Kim, C. S.; Lee, S. S.; Chen, Z.; Facchetti, A.; Toney, M. F.; Loo, Y. L. Chem. Mater. 2014, 26, 5020. doi: $10.1021 / \mathrm{cm} 502112 \mathrm{z}$ 